\title{
Differentiating Ewing's sarcoma from other round blue cell tumors using a RT-PCR translocation panel on formalin-fixed paraffin-embedded tissues
}

\author{
Tracey B Lewis ${ }^{1}$, Cheryl M Coffin ${ }^{1,2}$ and Philip S Bernard ${ }^{1,2,3}$ \\ ${ }^{1}$ The ARUP Institute for Clinical and Experimental Pathology, Salt Lake City, UT, USA; ${ }^{2}$ Department of \\ Pathology, University of Utah School of Medicine, Salt Lake City, UT, USA and ${ }^{3}$ Huntsman Cancer Institute, \\ University of Utah, Salt Lake City, UT, USA
}

\begin{abstract}
Ewing's sarcoma is a common malignancy of bone and soft tissue that occurs most often in children and young adults. Differentiating Ewing's sarcoma from other round blue cell tumors can be a diagnostic challenge because of their similarity in histology and clinical presentation. Thus, ancillary molecular tests for detecting disease-defining translocations are important for confirming the diagnosis. We analyzed 65 round blue cell tumors, including 53 Ewing's sarcoma samples from 50 unique cases. Samples were processed for RNA from archived formalin-fixed paraffin-embedded tissue blocks. Real-time RT-PCR assays specific for Ewing's sarcoma (EWS-FLI1, EWS-ERG, EWS-ETV1, EWS-ETV4, and EWS-FEV), synovial sarcoma (SYT-SSX1 and SYT-SSX2), and rhabdomyosarcoma (PAX3-FKHR and PAX7-FKHR) were tested across the samples. The translocation panel had a sensitivity of $81 \%$ (43 out of 53 samples) for diagnosing Ewing's sarcoma when using the histological criteria as the 'gold' standard. None of the Ewing's specific translocations were found in the non-Ewing's samples (100\% specificity). Of the 43 samples with translocations detected, 26 (60\%) had an EWSFLI1 type 1 translocation, $13(30 \%)$ had an EWS-FLI1 type 2 translocation, 3 (7\%) had an EWS-ERG translocation, 1 had an EWS-ETV1 translocation, and 1 sample had both an EWS-FLI1 type 1 and type 2 translocation. Our real-time RT-PCR assay for detecting sarcoma translocations has high sensitivity and specificity for Ewing's sarcoma and has clinical utility in differentiating small round blue cell tumors in the clinical lab.

Modern Pathology (2007) 20, 397-404. doi:10.1038/modpathol.3800755
\end{abstract}

Keywords: Ewing's sarcoma; translocation; molecular diagnostics; RT-PCR

Round blue cell tumors are a diverse group of cancers that include the Ewing's sarcoma family, rhabdomyosarcoma, poorly differentiated synovial sarcoma, desmoplastic sarcoma, neuroblastoma, and malignant lymphoma. ${ }^{1}$ Although these tumors share similar histology, the prognosis and treatment is vastly different. There are now a variety of molecular techniques that can help differentiate these tumor types. For instance, the histological diagnosis of Ewing's sarcoma can be corroborated with immunohistochemistry (CD99-positive, Fli1-positive $)^{2,3}$ or identification of specific chromosomal

Correspondence: Dr PS Bernard, Huntsman Cancer Institute, University of Utah, 2000 Circle of Hope, Suite 3345, Salt Lake City, UT 84105-5550, USA.

E-mail: phil.bernard@hci.utah.edu

Received 25 October 2006; revised 27 December 2006; accepted 29 December 2006 translocations using either fluorescence in situ hybridization or RT-PCR. ${ }^{4-6}$

Ewing's sarcoma commonly presents in adolescence, either at skeletal or extraskeletal sites, and there are often metastases at the time of diagnosis. Balanced translocations between the EWS gene and members of the ETS family are characteristic for Ewing's sarcoma. Approximately 85\% of cases have an EWS-FLI1 gene fusion in which the DNA-binding domain of the ETS transcript fuses to the transactivation domain of FLI1 (t(11;22)(q24;q12)). ${ }^{7,8}$ In $\sim 60 \%$ of cases with EWS-FLI1 translocations, exons 1-7 of EWS are fused to exons 6-9 of FLI1 (type 1 fusion). The remaining cases involving FLI1 result from EWS exons 1-7 joining to exons 5-9 of FLI1 (type 2 fusion). ${ }^{9}$ EWS translocations involving ERG as a fusion partner $(\mathrm{t}(22 ; 21)(\mathrm{q} 22 ; \mathrm{q} 12))$ are the second most common translocation in Ewing's, accounting for $\sim 10 \%$ of cases. ${ }^{7,10,11}$ Fusions between EWS and 
other ETS family members occur less frequently but are also specific for Ewing's: EWS-ETV1 $\mathrm{t}(7: 22)$, EWS-ETV4 $\mathrm{t}(17 ; 22), \quad E W S-F E V \quad \mathrm{t}(2 ; 22) .{ }^{12-15}$ Other mesenchymal tumors with specific translocations that should be considered in the differential diagnosis of Ewing's include alveolar rhabdomyosarcoma and synovial sarcoma.

Rhabdomyosarcoma is predominantly a disease of children and adolescents accounting for $5-8 \%$ of cancers in the pediatric population. Alveolar rhabdomyosarcoma is the most aggressive type of rhabdomyosarcoma and can be distinguished from embryonal rhabdomyosarcoma and other mesenchymal tumors by the detection of a $P A X-F K H R$ gene translocation. In $\sim 55 \%$ of alveolar rhabdomyosarcoma cases, the PAX3 gene on chromosome $2 \mathrm{q} 35$ is juxtaposed to the FKHR gene on chromosome 13q14. Fusions between $P A X 7$ on chromosome 1p36 and the FKHR gene account for $\sim 22 \%$ of cases. The specific translocation type, as well as the tumor type, has prognostic significance-alveolar rhabdomyosarcomas containing a PAX7-FKHR translocation are usually less invasive and have a better prognosis than those with the PAX3-FKHR gene fusion. ${ }^{16}$

Synovial sarcomas frequently present during the second decade of life and should be considered in the differential diagnosis along with other mesenchymal tumors that occur during adolescence. In synovial sarcoma, the $S Y T$ gene on chromosome 18 is fused to a member of the SSX gene family $(\mathrm{t}(\mathrm{X} ; 18)(\mathrm{p} 11 ; \mathrm{q} 11))$. The $S S X$ gene family contains nine members, all clustered on the X chromosome, with $S S X 1$ and $S S X 2$ being most often involved in synovial sarcoma. Fusion to the $S S X 1$ gene accounts for $\sim 64 \%$ of synovial sarcomas, whereas the $S S X 2$ gene is involved in the vast remainder of cases. Ladanyi et $a l^{17}$ have reported that cases involving the SYT-SSX1 gene fusion have a worse prognosis although a more recent study by Guillou and coworkers $^{18,19}$ found no significant correlation.

In this current study, 65 round blue cell tumors were analyzed using a real-time RT-PCR translocation panel for detecting gene fusion transcripts specific for Ewing's sarcoma (EWS-FLI1, EWS-ERG, EWS-ETV1, EWS-ETV4, and EWS-FEV), synovial sarcoma (SYT-SSX1 and SYT-SSX2), and rhabdomyosarcoma ( $P A X 3-F K H R$ and $P A X 7-F K H R$ ). Alternate splice sites were detected using either duallabeled probes or the dsDNA dye SYBR Green and post-amplification fluorescent melting curve analysis. Our translocation panel is accurate in detecting Ewing's sarcoma and has general utility in the clinical laboratory for the differentiating round blue cell tumors.

\section{Materials and methods}

\section{Cohorts}

Institutional Review Board approval was obtained from the University of Utah to study patients diagnosed with sarcoma at Primary Children's Medical Center (Salt Lake City, UT, USA) or the University of Utah Health Sciences Center. Diagnosis was established based on WHO defined histological criteria. ${ }^{20,21}$

\section{RNA Extraction and Reverse Transcription}

Full-face $10 \mu \mathrm{m}$ sections were cut from each formalin-fixed paraffin-embedded tissue block with a microtome and sections were stored in a microfuge tube at $-80^{\circ} \mathrm{C}$. A single unstained section from each block was deparaffinized with Hemo-De (Scientific Safety Products, Keller, TX, USA) and total cellular RNA was extracted using the High Pure RNA Paraffin Kit (Roche Applied Science, Indianapolis, IN, USA) according to the supplier's instructions. RNA was quantified on a NanoDrop ND-1000 Spectrophotometer (Wilmington, DE, USA) and concentrations greater than $30 \mathrm{ng} / \mu \mathrm{l}$ were considered acceptable for reverse transcription. Firststrand cDNA synthesis was performed from $500 \mathrm{ng}$ purified total RNA using Superscript III reverse transcriptase (1st Strand Kit, Invitrogen, Carlsbad, CA, USA) and gene specific primers (each anti-sense primer at $1 \mathrm{pmol} / \mu \mathrm{l}$ ) in a final volume of $25 \mu \mathrm{l}$. Each cDNA was diluted in TE (10 mM Tris- $\mathrm{HCl}, 0.1 \mathrm{mM}$ EDTA) to a concentration of $5 \mathrm{ng} / \mu \mathrm{l}$.

\section{Primers and Probes}

Two different real-time RT-PCR systems were employed for detecting transcripts. Dual-labeled probes were used in the assays for the housekeeper gene (MRPL19), the common gene fusions of Ewing's sarcoma (EWS-FLI1, type 1 and EWS-FLI1, type 2), and alveolar rhabdomyosarcoma (PAX3-FKHR and $P A X 7-F K H R$ ). The dsDNA dye SYBR Green was used for the more rare Ewing's translocations ( $E W S$ ERG, EWS-ETV1, EWS-ETV4, and EWS-FEV) and synovial sarcoma ( $S Y T-S S X 1$ and SYT-SSX2). Table 1 provides the primer and probe sequences, the amplicon length, and amplicon $T_{\mathrm{m}}$ (SYBR Green based assays only) for each system. A schematic showing primer and probe placement for each translocation assay is shown in Figure 1.

\section{Real-Time PCR}

The dual-labeled probe assays were performed in a final reaction volume of $25 \mu \mathrm{l}$ containing $12.5 \mu \mathrm{l}$ TaqMan Universal Master Mix (Applied Biosystems, Foster City, CA, USA), 10 ng cDNA, $0.25 \mu \mathrm{M}$ gene specific fluorescent probe (Operon, Huntsville, AL, USA), $0.5 \mu \mathrm{M}$ each forward and reverse primers (Operon, Huntsville, AL, USA), $0.5 \mathrm{mg} / \mu \mathrm{l}$ of bovine serum albumin (Sigma-Aldrich, catalogue \# B6917), and 0.1 U UNG (Applied Biosystems, Foster City, CA, USA). Uracil- $N$-glycosylase and dUTPs were 
Table 1 Primers and probes sequences

\begin{tabular}{|c|c|c|c|c|c|c|}
\hline Assay & Translocation & Forward primer & Reverse primer & Probe & $\begin{array}{c}\text { Amplicon } \\
(b p)\end{array}$ & $\mathrm{T}_{m}{ }^{\mathrm{a}}\left({ }^{\circ} \mathrm{C}\right)$ \\
\hline Housekeeper & MRPL19 & ggaagaggacttggagctact & tcctggacccgaggattat & caaatctcgacaccttgtccttcga & 95 & - \\
\hline \multirow[t]{6}{*}{ Ewing's sarcoma } & $\begin{array}{l}\text { EWS/FLI1, } \\
\text { type } 1\end{array}$ & ccaagtcaatatagccaacag & ggccagaattcatgttattgc & acgggcagcaga/acccttcttat & 100 & - \\
\hline & $\begin{array}{l}\text { EWS/FLI1, } \\
\text { type } 2\end{array}$ & ccaagtcaatatagccaacag & ggccagaattcatgttattgc & acgggcagcaga/gttcactgct & 166 & - \\
\hline & EWS/ERG & ccaagtcaatatagccaacag & tccaggaggaactgccaaag & SYBR Green & 154 & $88.49 \pm 0.17$ \\
\hline & EWS/ETV1 & acagccaagctccaagtc & tgtgggtccttcccgatac & SYBR Green & 98 & $83.32 \pm 0.18$ \\
\hline & EWS/ETV4 & tcctacagccaagctcc & gagaagccctctgtgtgg & SYBR Green & 104 & $85.00 \pm 0.16$ \\
\hline & EWS/FEV & tggtggacccatggatgaag & tcgggttcttcccgtccttg & SYBR Green & 80 & $82.87 \pm 0.11$ \\
\hline \multirow[t]{2}{*}{ Rhabdomyosarcoma } & PAX3/FKHR & ccgacagcagctctgcctac & tgaacttgctgtgtagggacag & cctctcacctcag/aattcaattcgtca & 171 & - \\
\hline & PAX7/FKHR & ccgacagcagctctgcctac & tgaacttgctgtgtagggacag & acggcctgtctcctcag/aattcaatt & 159 & - \\
\hline \multirow[t]{2}{*}{ Synovial sarcoma } & SYT/SSX1 & ccagcagaggccttatggata & acactcccttcgaatcattttcg & SYBR Green & 77 & $82.67 \pm 0.26$ \\
\hline & SYT/SSX2 & ccagcagaggccttatggata & gcacttcctccgaatcatttcct & SYBR Green & 77 & $80.98 \pm 0.34$ \\
\hline
\end{tabular}

${ }^{\mathrm{a}} T_{\mathrm{m}}$ range based on 2 s.d. from the mean across three separate runs.

a EWS/FLI1, type 1

$100 \mathrm{bp}$ amplicon

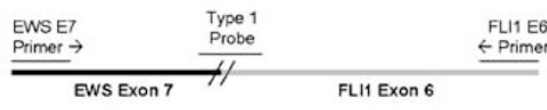

EWS/FLI1, type 2

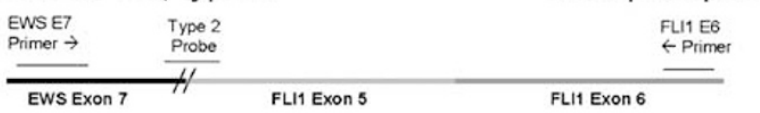

EWS/ERG

$154 \mathrm{bp}$ amplicon

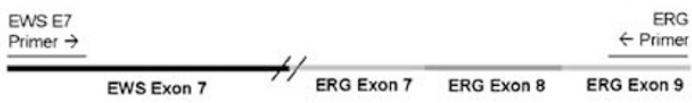

\section{b SYT/SSX 1 or 2}

77 bp amplicon

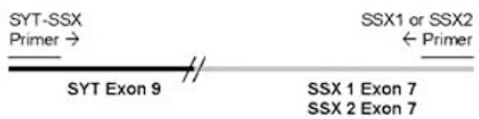

C PAX3/FOXOA1A

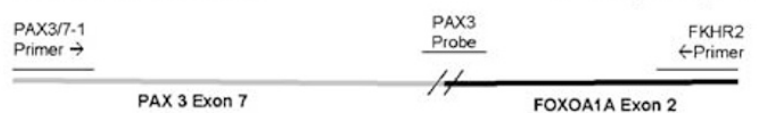

\section{PAX7/FOXOA1A}

159 bp amplicon

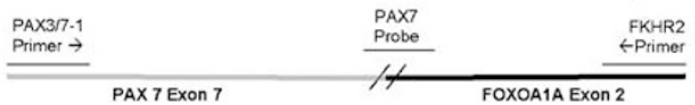

Figure 1 A schematic showing primer and probe placement for different sarcoma translocations. (a) Representation of the Ewing's EWS-FLI1 type 1, EWS-FLI1 type 2, and EWS-ERG assays. The type 1 and type 2 EWS-FLI1 translocations are identified during real-time PCR using fusion-specific dual-labeled probes, whereas the EWS-ERG translocation is identified by a characteristic $T_{\mathrm{m}}$ using fluorescent melting curve analysis. (b) The SYT-SSX translocations are identified using a common forward SYT primer and a reverse primer specific for either SSX1 or SSX2, which are placed in separate reactions. (c) The PAX-FKHR translocations are amplified using the same forward and reverse primers and fusion-specific dual-labeled probes differentiate the PAX3-FKHR from the PAX7-FKHR fusion. included in all PCR master mixes to prevent the possibility of subsequent re-amplification of PCR products. Each sample was amplified in duplicate in the LightCycler (Roche). Prior to amplification, each run was held at $50^{\circ} \mathrm{C}$ for 5 min (UNG step) in order to remove any contaminating amplicon. A two-step amplification was performed using an initial denaturation step ( $95^{\circ} \mathrm{C}$ for $5 \mathrm{~min}$ ) followed by 50 cycles of denaturation $\left(95^{\circ} \mathrm{C}\right.$ for $\left.15 \mathrm{~s}\right)$ and annealing/ extension $\left(60^{\circ} \mathrm{C}\right.$ for $\left.1 \mathrm{~min}\right)$. Fluorescence $(494 \mathrm{~nm})$ was acquired each cycle during the annealing/ extension phase.

The SYBR Green assays (EWS-ERG, EWS-ETV1, EWS-ETV4, EWS-FEV, SYT-SSX1, and SYT-SSX2) were performed in a final reaction volume of $20 \mu \mathrm{l}$ containing $1 \times$ PCR buffer 3 (Idaho Technology, Salt Lake City, UT, USA), $10 \mathrm{ng}$ cDNA, $0.5 \mu \mathrm{M}$ each forward and reverse primers, $0.2 \mathrm{mM}$ each of dATP, dCTP, and dGTP, $0.1 \mathrm{mM}$ dTTP, $0.3 \mathrm{mM}$ dUTP (Applied Biosystems, Foster City, CA, USA), 0.1 U UNG (Applied Biosystems, Foster City, CA, USA), $0.2 \mathrm{U}$ Taq (Invitrogen, Carlsbad, CA, USA), and SYBR Green (Molecular Probes/Invitrogen, Carlsbad, CA, USA) at a 1/3000 dilution. PCR reactions were carried out in the LightCycler using an initial UNG step $\left(50^{\circ} \mathrm{C}\right.$ for $\left.5 \mathrm{~min}\right)$ followed by a denaturation step $\left(95^{\circ} \mathrm{C}\right.$ for $5 \mathrm{~min}$ ) and 50 cycles of denaturation $\left(94^{\circ} \mathrm{C}\right.$ for $\left.3 \mathrm{~s}\right)$, annealing $\left(58^{\circ} \mathrm{C}\right.$ for $\left.6 \mathrm{~s}\right)$, and extension $\left(72^{\circ} \mathrm{C}\right.$ for $\left.6 \mathrm{~s}\right)$. A post-amplification melting curve analysis was carried out immediately following PCR by heating to $94^{\circ} \mathrm{C}$ for $15 \mathrm{~s}$, rapidly cooling to $45^{\circ} \mathrm{C}$ for $15 \mathrm{~s}$, and slowly heating to $97^{\circ} \mathrm{C}$ at $0.1^{\circ} \mathrm{C} / \mathrm{s}$ while continuously monitoring fluorescence $(494 \mathrm{~nm})$.

\section{Controls}

As a control for cDNA synthesis and sample quality, each sample was reverse transcribed and amplified for the housekeeper gene MRPL19. ${ }^{22}$ All samples 
were assayed in duplicate, and positive and negative controls were included for each translocation. Samples with a RT-PCR crossing threshold greater than 35 for the housekeeper gene were excluded from further analysis. Positive controls consisted of cell lines, plasmid constructs, and sequence-verified patient samples (Table 2).

The A673 cell line was used as a positive control for the EWS-FLI1, type 1 translocation. Interestingly, A673 was originally thought to be derived from a rhabdomyosarcoma until it was found to have a characteristic Ewing's sarcoma translocation. ${ }^{23}$ The cell line RDES was used as a control for the EWSFLI1, type 2 translocation (http://www.biotech.ist. unige.it/cldb/cl4129.html). Plasmids containing cDNA sequences surrounding the breakpoints for EWS-ERG, EWS-ETV1 and EWS-ETV4 were used as controls for the remaining Ewing's translocations.

The cell line FU-SY-1 (SYT-SSX1) and a sequence confirmed sample (SYT-SSX2) were used as positive controls for synovial sarcoma. Controls for human alveolar rhabdomyosarcoma included the cell lines SJRH30 and CW9019, known to contain the PAX3FKHR and PAX7-FKHR translocations respectively. ${ }^{24}$

\section{Results}

There were initially 69 Ewing's sarcoma samples extracted for RNA from formalin-fixed paraffinembedded tissue. Twelve (17\%) failed RNA extraction and $4(6 \%)$ were excluded due to poor sample quality as determined by a late $\mathrm{Cp}(>35)$ for the housekeeper control gene. Failure in extraction or PCR was not associated with sample age. Forty-three out of $53(81 \%)$ Ewing's samples had a detectable EWS translocation by RT-PCR (Table 2). Of the 43 samples with translocations detected, $26(60 \%)$ had an EWS-FLI1 type 1 translocation, $13(30 \%)$ had an EWS-FLI1 type 2 translocation, $3(7 \%)$ had an EWSERG translocation, 1 had an EWS-ETV1 translocation, and 1 sample had both an EWS-FLI1 type 1 and type 2 translocation. Figure 2 shows typical results for detecting EWS-FLI1 variants with fusion-specific dual-labeled probes, and detecting the EWS-ERG and SYT-SSX gene fusions by fluorescent melting curve analysis.

There were 50 unique cases of Ewing's, since two patients had multiple samples. Out of 50 patients with a diagnosis of Ewing's, 41 (82\%) had an EWS translocation detected in at least one of their samples. One of the subjects in which replicate samples were obtained had an EWS-FLI1 type 2 translocation in the primary (femur) and an EWSFLI1 type 1 translocation in the metastasis (chest wall). Another subject had three samples with two of the blocks positive for the EWS-FLI1 type 2 translocation and the other block with no detectable transcript.

Sensitivity (TP/(TP + FN)) and specificity (TN/ $(\mathrm{TN}+\mathrm{FP}))$ of the RT-PCR translocation panel was determined for Ewing's sarcoma using the histological diagnosis as the gold standard. Ewing's samples that had no detectable EWS translocation were tested on the extended translocation panel and none had a translocation of another type. In addition, the translocation panel was tested on other round blue cell samples (two neuroblastomas, one leiomyosarcoma, one desmoplastic sarcoma, three synovial sarcomas, and four rhabdomyosarcomas samples) and there were no false positives. Overall, the translocation panel had $81 \%$ sensitivity and $100 \%$ specificity for Ewing's.

\section{Discussion}

Round blue cell tumors can have considerable overlap in epidemiology, histology, and immunophenotype. For instance, rhabdomyosarcomas that lack myoblastic differentiation can be difficult to distinguish from other round cell neoplasms, such as Ewing's. In addition, synovial sarcomas may have a spectrum of morphologies from spindle shaped to rounder epithelial-like cells, which can resemble other mesenchymal and non-mesenchymal tumors. Immunohistochemical markers can assist in the differential diagnosis, but the current panels have limitations in specificity. ${ }^{25}$ For this reason, fluorescence in situ hybridization has been useful in difficult cases. For instance, there have been several reported cases of sarcomas suspected to be desmoplastic small round cell tumors or osteosarcomas that upon translocation analyses were shown to have characteristic Ewing's EWS-FLI1 translocations. ${ }^{26-29}$ Although fluorescence in situ hybridization break-apart probes are commonly employed clinically, most assays do not discern the specific fusion type (eg EWS-FLI1 type 1 and type 2). ${ }^{5,30}$

Using our RT-PCR translocation panel, we found that $81 \%$ of the Ewing's samples had an EWS translocation, consistent with previous reports estimating the frequency at $85 \%{ }^{7,8}$ There were an additional 16 Ewing's samples that were rejected due to low RNA quality or quantity. These samples are removed from the analyses upfront so that they do not affect the sensitivity of the assay. While most of the Ewing's samples had an EWS-FLI1 translocation, we also detected the EWS-ERG gene fusion in three samples and the EWS-ETV1 gene fusion in one sample. No samples had translocations involving the EWS-FEV or EWS-ETV4 translocations, which others have only rarely detected. ${ }^{12-15,31}$ Finally, none of our 11 non-Ewing's samples had an EWS fusion.

In a single case, we found EWS-FLI1 type 1 and type 2 fusion transcripts coexisting in the same sample. The coexistence of defining translocations in Ewing's sarcoma and synovial sarcoma patients has been previously reported. ${ }^{1,32}$ Different fusion transcripts identified in the same patient could be explained by independent chromosomal fusion events or alternate splicing events that occur either 
Table 2 Clinico-pathological information

\begin{tabular}{|c|c|c|c|c|c|c|}
\hline Case & $\begin{array}{c}\text { Patient age } \\
\text { (in years) }\end{array}$ & Gender & Site & Histological diagnosis & Translocation & $\begin{array}{l}\text { Age of block } \\
\text { (in years) }\end{array}$ \\
\hline EWS1 & 18 & $\mathrm{M}$ & Pelvis & Ewing's Sarcoma & EWS-FLI1, type 1 & 3 \\
\hline EWS2 & 15 & $\mathrm{M}$ & Presacral soft tissue & Ewing's Sarcoma & EWS-FLI1, type 1 & 1 \\
\hline EWS3 & 20 & $\mathrm{M}$ & Calf & Ewing's Sarcoma & EWS-FLI1, type 1 & 8 \\
\hline EWS4 & 9 & $\mathrm{M}$ & Abdomen & Ewing's Sarcoma & EWS-FLI1, type 1 & 6 \\
\hline EWS5 & 7 & $\mathrm{~F}$ & Left buttock & Ewing's Sarcoma & EWS-FLI1, type 1 & 2 \\
\hline EWS6 & 11 & $\mathrm{M}$ & Temporal lobe & Ewing's Sarcoma & EWS-FLI1, type 1 & 6 \\
\hline EWS7 & 16 & $\mathrm{M}$ & Left femur & Ewing's Sarcoma & EWS-FLI1, type 1 & 12 \\
\hline EWS8 & 21 & $\mathrm{~F}$ & Right 10 th rib & Ewing's Sarcoma & EWS-FLI1, type 1 & 12 \\
\hline EWS9 & 15 & $\mathrm{M}$ & Cranium & Ewing's Sarcoma & EWS-FLI1, type 1 & 7 \\
\hline EWS10 & 13 & $\mathrm{~F}$ & Spine & Ewing's Sarcoma & EWS-FLI1, type 1 & 1 \\
\hline EWS11 & 8 & $\mathrm{~F}$ & Spinal canal T8-L3 & Ewing's Sarcoma & EWS-FLI1, type 1 & 15 \\
\hline EWS12 & 6 & $\mathrm{~F}$ & Left femur & Ewing's Sarcoma & EWS-FLI1, type 1 & 8 \\
\hline EWS13 & 12 & $\mathrm{~F}$ & Right kidney & Ewing's Sarcoma & EWS-FLI1, type 1 & 2 \\
\hline EWS14 & 14 & $\mathrm{M}$ & Right fibula & Ewing's Sarcoma & EWS-FLI1, type 1 & 4 \\
\hline EWS15 & 18 & $\mathrm{M}$ & Right chest and rib & Ewing's Sarcoma & EWS-FLI1, type 1 & 1 \\
\hline EWS16 & 17 & $\mathrm{M}$ & Ilium & Ewing's Sarcoma & EWS-FLI1, type 1 & 8 \\
\hline EWS17 & 1 & $\mathrm{M}$ & Right scapula & Ewing's Sarcoma & EWS-FLI1, type 1 & 4 \\
\hline EWS18 & 11 & $\mathrm{M}$ & Brain metastasis from left $3 \mathrm{rd}$ rib & Ewing's Sarcoma & EWS-FLI1, type 1 & 1 \\
\hline EWS19 & 22 & $\mathrm{M}$ & Right 2nd rib & Ewing's Sarcoma & EWS-FLI1, type 1 & 8 \\
\hline EWS20 & 18 & $\mathrm{M}$ & Right thigh & Ewing's Sarcoma & EWS-FLI1, type 1 & 1 \\
\hline EWS21 & 17 & $\mathrm{M}$ & Right lung lower lobe & Ewing's Sarcoma & EWS-FLI1, type 1 & 3 \\
\hline EWS22 & 20 & $\mathrm{M}$ & Right pelvis & Ewing's Sarcoma & EWS-FLI1, type 1 & 3 \\
\hline EWS23 & 20 & $\mathrm{M}$ & Sternum & Ewing's Sarcoma & EWS-FLI1, type 1 & 2 \\
\hline EWS24-m ${ }^{a}$ & 20 & $\mathrm{~F}$ & Metastasis right chest wall & Ewing's Sarcoma & EWS-FLI1, type 1 & 10 \\
\hline EWS25 & 16 & $\mathrm{~F}$ & Left thigh & Ewing's Sarcoma & EWS-FLI1, type 1 & 12 \\
\hline EWS26 & 13 & $\mathrm{M}$ & Right femur & Ewing's Sarcoma & EWS-FLI1, type 1 & 6 \\
\hline EWS27 & 14 & $\mathrm{M}$ & Right knee & Ewing's Sarcoma & EWS-FLI1, type 2 & 4 \\
\hline EWS35- $\mathrm{p}^{\mathrm{b}}$ & 16 & $\mathrm{M}$ & Right scapula & Ewing's Sarcoma & EWS-FLI1, type 2 & 4 \\
\hline EWS28 & 23 & $\mathrm{M}$ & Left groin & Ewing's Sarcoma & EWS-FLI1, type 2 & 11 \\
\hline EWS29 & 16 & $\mathrm{M}$ & Right ilium & Ewing's Sarcoma & EWS-FLI1, type 2 & 2 \\
\hline EWS30 & 14 & $\mathrm{~F}$ & Right ilium & Ewing's Sarcoma & EWS-FLI1, type 2 & 6 \\
\hline EWS31 & 23 & $\mathrm{M}$ & Right ilium & Ewing's Sarcoma & EWS-FLI1, type 2 & 6 \\
\hline EWS32 & 23 & $\mathrm{~F}$ & Left flank & Ewing's Sarcoma & EWS-FLI1, type 2 & 12 \\
\hline EWS33 & 10 & $\mathrm{~F}$ & Right humerus & Ewing's Sarcoma & EWS-FLI1, type 2 & 7 \\
\hline EWS34 & 15 & $\mathrm{M}$ & Left neck & Ewing's Sarcoma & EWS-FLI1, type 2 & 3 \\
\hline EWS35-lr & 18 & $\mathrm{M}$ & Right scapula & Ewing's Sarcoma & EWS-FLI1, type 2 & 2 \\
\hline EWS36 & 9 & $\mathrm{M}$ & Left scapula & Ewing's Sarcoma & EWS-FLI1, type 2 & 2 \\
\hline EWS37 & 20 & $\mathrm{~F}$ & Pelvis & Ewing's Sarcoma & EWS-FLI1, type 2 & 11 \\
\hline EWS24- $\mathrm{p}^{\mathrm{a}}$ & 16 & $\mathrm{~F}$ & Left femur & Ewing's Sarcoma & EWS-FLI1, type 2 & 14 \\
\hline EWS38 & 26 & $\mathrm{~F}$ & Third and 4th ribs & Ewing's Sarcoma & EWS-ERG & 15 \\
\hline EWS39 & 15 & $\mathrm{~F}$ & Left fibula & Ewing's Sarcoma & EWS-ERG & 2 \\
\hline EWS40 & 12 & $\mathrm{~F}$ & Left 3rd rib & Ewing's Sarcoma & EWS-ERG & 10 \\
\hline EWS41 & 2 & $\mathrm{M}$ & Back & Ewing's Sarcoma & EWS-ETV1 & 2 \\
\hline EWS42 & 10 & $\mathrm{M}$ & Left calcaneus & Ewing's Sarcoma & Negative & 3 \\
\hline EWS43 & 7 & $\mathrm{M}$ & Paraspinal & Ewing's Sarcoma & Negative & 4 \\
\hline EWS44 & 18 & $\mathrm{M}$ & Left chest wall & Ewing's Sarcoma & Negative & 13 \\
\hline EWS35- $\mathrm{p}^{\mathrm{b}}$ & 16 & $\mathrm{M}$ & Right scapula & Ewing's Sarcoma & Negative & 4 \\
\hline EWS45 & 1 & $\mathrm{M}$ & Calf & Ewing's Sarcoma & Negative & 2 \\
\hline EWS46 & 12 & $\mathrm{M}$ & Right buttock & Ewing's Sarcoma & Negative & 6 \\
\hline EWS47 & 17 & $\mathrm{M}$ & Right pelvis & Ewing's Sarcoma & Negative & 5 \\
\hline EWS48 & 21 & $\mathrm{M}$ & Right pelvis & Ewing's Sarcoma & Negative & 8 \\
\hline EWS49 & 25 & $\mathrm{M}$ & Right pelvis & Ewing's Sarcoma & Negative & 13 \\
\hline EWS50 & 11 & $\mathrm{M}$ & Right temporal & Ewing's Sarcoma & Negative & 14 \\
\hline A 673 & NA & NA & Control cell line & Ewing's Sarcoma & EWS-FLI1, type 1 & NA \\
\hline $03-344$ & NA & NA & Control sample & Ewing's Sarcoma & EWS-FLI1, type 1 & NA \\
\hline RDES & NA & NA & Control cell line & Ewing's Sarcoma & EWS-FLI1, type 2 & NA \\
\hline $02-060$ & NA & NA & Control sample & Ewing's Sarcoma & EWS-FLI1, type 2 & NA \\
\hline $03-1434$ & NA & NA & Control sample & Neuroblastoma & Negative & NA \\
\hline $03-1359$ & NA & NA & control sample & Neuroblastoma & Negative & NA \\
\hline $02-415$ & NA & NA & Control sample & Leiomyosarcoma & Negative & NA \\
\hline $03-558$ & NA & NA & Control sample & Desmoplastic sarcoma & Negative & NA \\
\hline $03-556$ & NA & NA & Control sample & Synovial sarcoma & SYT-SSX2 & NA \\
\hline $03-563$ & NA & NA & Control sample & Synovial sarcoma & SYT-SSX1 & NA \\
\hline FU-SY-1 & NA & NA & Control cell line & Synovial sarcoma & SYT-SSX1 & NA \\
\hline SJRH30 & NA & NA & Control cell line & Rhabdomyosarcoma & PAX3-FKHR & NA \\
\hline PCO32 & NA & NA & Control cell line & Rhabdomyosarcoma & PAX3-FKHR & NA \\
\hline CW9019 & NA & NA & Control cell line & Rhabdomyosarcoma & PAX7-FKHR & NA \\
\hline PC033 & NA & NA & Control cell line & Rhabdomyosarcoma & PAX7-FKHR & NA \\
\hline
\end{tabular}

$\mathrm{m}=$ metastatic $; \mathrm{p}=$ primary $; \mathrm{lr}=$ local reoccurance NA $=$ not applicable.

${ }^{\mathrm{a}}$ EWS 24.

${ }^{\mathrm{b}} \mathrm{EWS} 35$. 

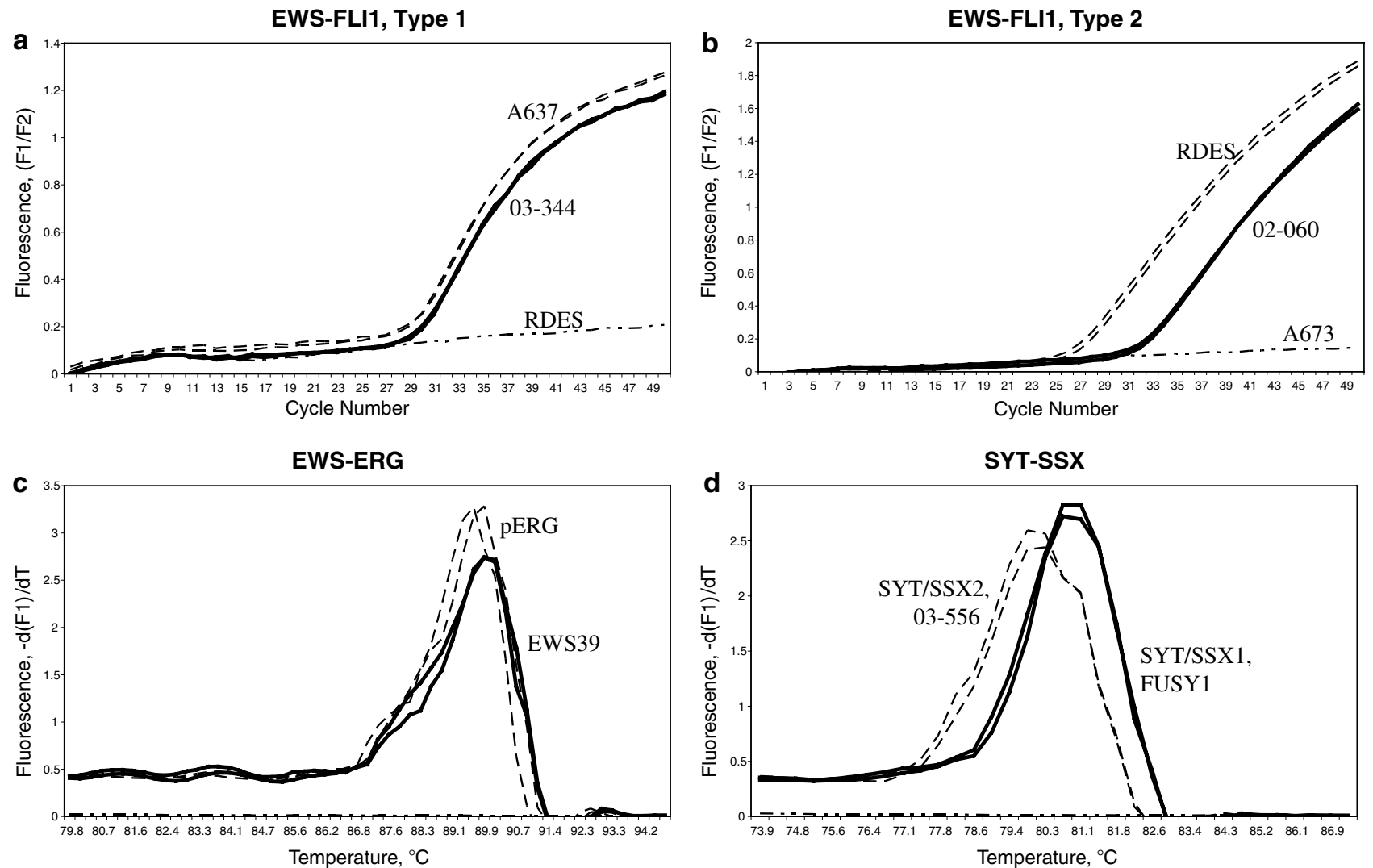

Figure 2 Detection and differentiation of Ewing's and synovial sarcoma translocations by amplification curves and $T_{\mathrm{m}}$. Each sample is run in duplicate. (a) A plot of fluorescence vs cycle number shows amplification curves specific for EWS-FLI1 type 1 in the cell line (A673) and the patient sample (03-344), while no amplification is seen in the RDES cell line containing the type 2 translocation. (b) The cell line RDES and the patient sample 02-060 show amplification curves specific for EWS-FLI1 type 2 translocation, while no amplification is seen in the A673 cell line containing the type 1 translocation. (c) Samples are PCR amplified in the presence of the dsDNA dye SYBR Green and post-amplification melting curve analysis is performed. A plot of dF/dT vs fluorescence shows a characteristic $T_{\mathrm{m}}$ for the control plasmid (pERG) and the patient sample (EWS39) containing an EWS-ERG translocation. Non-Ewing's sarcoma samples are negative. (d) The SYT-SSX genes are reverse transcribed using common primers and amplified using primers specific for SSX1 and SSX2. Fluorescent melting curve analysis distinguishes SYT-SSX1 (FUSY1) from SYT-SSX2 (03-556) by a reproducible $T_{\mathrm{m}}$ shift of $0.5^{\circ} \mathrm{C}$.

in the same or different cells. Bielack et $a l^{33}$ have reported a case of two primary Ewing's sarcomas in the same patient defined by different translocations, suggesting that the translocations were independent events arising from different clones. Here, we report a case with a type 2 translocation in the primary and a type 1 in the metastasis. Assuming that the metastasis arose from the primary, it suggests that either there was another chromosomal fusion event and the first translocation was lost from the cell or there was a switch in the splicing. It is uncertain whether the loss of exon 5 contributed to the metastatic potential or whether other alterations were responsible.

Studies have suggested that the EWS fusion type may have prognostic importance, with type 1 being associated with lower proliferation and an improved outcome in patients with localized disease. ${ }^{34-36}$ However, outcome differences in Ewing's patients based on fusion type have been statistically difficult to show due to the rarity of the disease and previous technical challenges in resolving the different fusion types. Large-scale retrospective studies will need to be carried out to determine if our assay has prognostic, as well as diagnostic, value.

A variety of real-time PCR techniques have been used for identifying translocations in hematological malignancies and soft tissue tumors. For instance, dual-labeled probes have been used to detect translocations in chronic myeloid leukemia (BCR-ABL transcript) and synovial sarcoma (SYT$S S X$ transcripts), ${ }^{37-39}$ and fluorescent melting curve analysis has been used to detect the MBR-JH translocation in follicular lymphoma. ${ }^{40}$ The decision whether to use sequence specific probes or a dsDNA dye as a probe depends on the sequences of the fusion partners and the resolution needed to distinguish different fusion types. In general, dsDNA probes are less expensive and technically easier, making them an attractive alternative to sequence-specific probes. We found that we could distinguish different SYT-SSX fusions using fluor- 
escent melting curve analysis and the dsDNA dye SYBR Green. This was possible since the SSX1 and $S S X 2$ sequences varied enough to create a characteristic $T_{\mathrm{m}}$ for each fusion type. In contrast, the EWS-FLI1 fusions were best distinguished by sequence-specific probes.

The advantages of using real-time PCR over conventional PCR with gel electrophoresis are that there is increased sensitivity, less sample manipulation, faster results, and the potential for quantification. For instance, monitoring the amount of BCR$A B L$ transcript in the blood and bone marrow has been useful for detecting relapse in chronic myeloid leukemia. ${ }^{37,38}$ Thus, our translocation assays could also be used quantitatively for monitoring minimal residual disease in sarcomas.

In conclusion, we have developed a translocation panel accurate in detecting Ewing's sarcoma, synovial sarcoma, and rhabdomysarcoma. Our real-time RT-PCR assays allow rapid detection of translocations specific for these sarcomas. The identification of the different gene fusion partners may add prognostic value to existing fluorescence in situ hybridization assays. The RT-PCR panel has utility in the clinical laboratory for diagnosing of sarcomas from formalin-fixed paraffin-embedded tissue and could potentially be used for monitoring minimal residual disease.

\section{Acknowledgements}

We thank Dr Stephen Lessnick for his generous gift of plasmid controls for EWS-ERG, EWS-ETV1, EWSETV4, EWS-FEV, and Dr David Joyner for control samples. This work was in part funded by the ARUP Institute for Experimental and Clinical Pathology.

\section{References}

1 Yoshino N, Kojima T, Asami S, et al. Diagnostic significance and clinical applications of chimeric genes in Ewing's sarcoma. Biol Pharm Bull 2003;26: 585-588.

2 Llombart-Bosch A, Navarro S. Immunohistochemical detection of EWS and FLI-1 proteinss in Ewing sarcoma and primitive neuroectodermal tumors: comparative analysis with CD99 (MIC-2) expression. Appl Immunohistochem Mol Morphol 2001;9: 255-260.

3 Rossi S, Orvieto E, Furlanetto A, et al. Utility of the immunohistochemical detection of FLI-1 expression in round cell and vascular neoplasm using a monoclonal antibody. Mod Pathol 2004;17:547-552.

4 Mangham DC, Williams A, McMullan DJ, et al. Ewing's sarcoma of bone: the detection of specific transcripts in a large, consecutive series of formalin-fixed, decalcified, paraffin-embedded tissue samples using the reverse transcriptase-polymerase chain reaction. Histopathology 2006;48:363-376.

5 Bridge RS, Rajaram V, Dehner LP, et al. Molecular diagnosis of Ewing sarcoma/primitive neuroectoder- mal tumor in routinely processed tissue: a comparison of two FISH strategies and RT-PCR in malignant round cell tumors. Mod Pathol 2006;19:1-8.

6 Fritsch MK, Bridge JA, Schuster AE, et al. Performance characteristics of a reverse transcriptase-polymerase chain reaction assay for the detection of tumor-specific fusion transcripts from archival tissue. Pediatr Dev Pathol 2003;6:43-53.

7 Zucman J, Melot T, Desmaze C, et al. Combinatorial generation of variable fusion proteins in the Ewing family of tumours. EMBO J 1993;12:4481-4487.

8 Dowing J, Head DR, Parham DM, et al. Detection of the $(11 ; 22)(q 24 ; q 12)$ translocation of Ewing's sarcoma peripheral neuroectodermal tumor by reverse transcription polymerase chain reaction. Am J Pathol 1993;143:1294-1300.

9 Parija T, Shirley S, Uma S, et al. Type 1 (11;22) (q24:q12) translocation is common in Ewing's sarcoma/ peripheral neuroectodermal tumour in South Indian patients. J Biosci 2005;30:371-376.

10 Peter M, Mugneret F, Aurias A, et al. An EWS/ERG fusion with a truncated N-terminal domain of EWS in a Ewing's tumor. Int J Cancer 1996;67:339-342.

11 Sorensen PH, Lessnick SL, Lopez-Terrada D, et al. A second Ewing's sarcoma translocation, $t(21 ; 22)$, fuses the EWS gene to another ETS-family transcription factor, ERG. Nat Genet 1994;6:146-151.

12 Jeon IS, Davis JN, Braun BS, et al. A variant Ewing's sarcoma translocation $(7 ; 22)$ fuses the EWS gene to the ETS gene ETV1. Oncogene 1995;10:1229-1234.

13 Peter $M$, Couturier J, Pacquement $\mathrm{H}$, et al. A new member of the ETS family fused to EWS in Ewing tumors. Oncogene 1997;14:1159-1164.

14 Kaneko Y, Yoshida K, Handa M, et al. Fusion of an ETS-family gene, EIAF, to EWS by $\mathrm{t}(17 ; 22)(\mathrm{q} 12 ; \mathrm{q} 12)$ chromosome translocation in an undifferentiated sarcoma of infancy. Genes Chromosomes Cancer 1996;15: 115-121.

15 Urano F, Umezawa A, Hong W, et al. A novel chimera gene between EWS and E1A-F, encoding the adenovirus E1A enhancer-binding protein, in extraosseous Ewing's sarcoma. Biochem Biophys Res Commun 1996;219:608-612.

16 Sorensen PH, Lynch JC, Qualman SJ, et al. PAX3-FKHR and PAX7-FKHR gene fusions are prognostic indicators in alveolar rhabdomyosarcoma: a report from the children's oncology group. J Clin Oncol 2002;20: 2672-2679.

17 Ladanyi M, Antonescu CR, Leung DH, et al. Impact of SYT-SSX fusion type on the clinical behavior of synovial sarcoma: a multi-institutional retrospective study of 243 patients. Cancer Res 2002;62: 135-140.

18 Guillou L, Benhattar J, Bonichon F, et al. Histologic grade, but not SYT-SSX fusion type, is an important prognostic factor in patients with synovial sarcoma: a multicenter, retrospective analysis. J Clin Oncol 2004; 22:4040-4050.

19 Ladanyi M. Correlates of SYT-SSX fusion type in synovial sarcoma: getting more complex but also more interesting? J Clin Oncol 2005;23:3638-3639; author reply 3639-3640.

20 Fletcher CD. The evolving classification of soft tissue tumours: an update based on the new WHO classification. Histopathology 2006;48:3-12.

21 Fletcher CDM, Unni K, Mertens F, (eds.) World Health Organisation Classification of Tumours. Pathology and 
Genetics of Tumours of Soft Tissue and Bone. IARC Press: Lyon, 2002.

22 Szabo A, Perou CM, Karaca M, et al. Statistical modeling for selecting housekeeper genes. Genome Biol 2004;5:R59.

23 Martinez-Ramirez A, Rodriguez-Perales S, Melendez $\mathrm{B}$, et al. Characterization of the A673 cell line (Ewing tumor) by molecular cytogenetic techniques. Cancer Genet Cytogenet 2003;141:138-142.

24 Davis RJ, Barr FG. Fusion genes resulting from alternative chromosomal translocations are overexpressed by gene-specific mechanisms in alveolar rhabdomyosarcoma. Proc Natl Acad Sci USA 1997;94: 8047-8051.

25 Olsen SH, Thomas DG, Lucas DR. Cluster analysis of immunohistochemical profiles in synovial sarcoma, malignant peripheral nerve sheath tumor, and Ewing sarcoma. Mod Pathol 2006.

26 Ordi J, de Alava E, Torne A, et al. Intraabdominal desmoplastic small round cell tumor with EWS/ERG fusion transcript. Am J Surg Pathol 1998;22:1026-1032.

27 Gardner LJ, Ayala AG, Monforte HL, et al. Ewing sarcoma/peripheral primitive neuroectodermal tumor: adult abdominal tumors with an Ewing sarcoma gene rearrangement demonstrated by fluorescence in situ hybridization in paraffin sections. Appl Immunohistochem Mol Morphol 2004;12:160-165.

28 Katz RL, Quezado M, Senderowicz AM, et al. An intraabdominal small round cell neoplasm with features of primitive neuroectodermal and desmoplastic round cell tumor and a EWS/FLI-1 fusion transcript. Hum Pathol 1997;28:502-509.

29 Oshima Y, Kawaguchi S, Nagoya S, et al. Abdominal small round cell tumor with osteoid and EWS/FLI1. Hum Pathol 2004;35:773-775.

30 Yamaguchi U, Hasegawa T, Morimoto Y, et al. A practical approach to the clinical diagnosis of Ewing's sarcoma/primitive neuroectodermal tumour and other small round cell tumours sharing EWS rearrangement using new fluorescence in situ hybridisation probes for
EWSR1 on formalin fixed, paraffin wax embedded tissue. J Clin Pathol 2005;58:1051-1056.

31 Olsen SH, Thomas DG, Lucas DR. Cluster analysis of immunohistochemical profiles in synovial sarcoma, malignant peripheral nerve sheath tumor, and Ewing sarcoma. Mod Pathol 2006;19:659-668.

32 Yang K, Lui WO, Xie Y, et al. Co-existence of SYTSSX1 and SYT-SSX2 fusions in synovial sarcomas. Oncogene 2002;21:4181-4190.

33 Bielack SS, Paulussen M, Kohler G. A patient with two Ewing's sarcomas with distinct EWS fusion transcripts. N Engl J Med 2004;350:1364-1365.

34 de Alava E, Kawai A, Healey JH, et al. EWS-FLI1 fusion transcript structure is an independent determinant of prognosis in Ewing's sarcoma. J Clin Oncol 1998;16:1248-1255.

35 Zoubek A, Dockhorn-Dworniczak B, Delattre O, et al. Does expression of different EWS chimeric transcripts define clinically distinct risk groups of Ewing tumor patients? J Clin Oncol 1996;14:1245-1251.

36 Aryee DN, Sommergruber W, Muehlbacher K, et al. Variability in gene expression patterns of Ewing tumor cell lines differing in EWS-FLI1 fusion type. Lab Invest 2000;80:1833-1844.

37 Amabile M, Giannini B, Testoni N, et al. Real-time quantification of different types of bcr-abl transcript in chronic myeloid leukemia. Haematologica 2001;86: 252-259.

38 Branford S, Hughes TP, Rudzki Z. Monitoring chronic myeloid leukaemia therapy by real-time quantitative PCR in blood is a reliable alternative to bone marrow cytogenetics. Br J Haematol 1999;107:587-599.

39 Bijwaard KE, Fetsch JF, Przygodzki R, et al. Detection of SYT-SSX fusion transcripts in archival synovial sarcomas by real-time reverse transcriptase-polymerase chain reaction. J Mol Diagn 2002;4:59-64.

40 Bohling SD, King TC, Wittwer CT, et al. Rapid simultaneous amplification and detection of the MBR/JH chromosomal translocation by fluorescence melting curve analysis. Am J Pathol 1999;154:97-103. 